\title{
LASNEX Modeling of Target Expansion in the ETA-II Experiment
}

Darwin D.-M. Ho

May 20, 1998

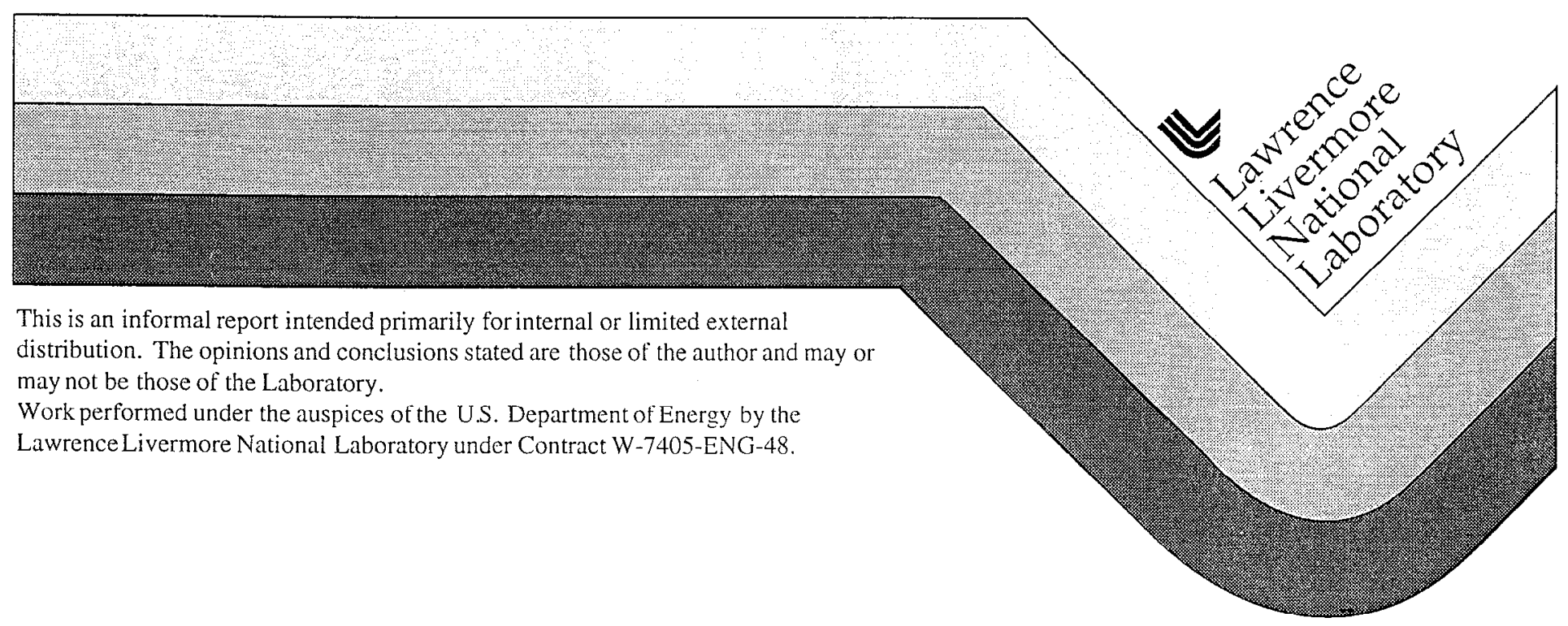




\section{DISCLAIMER}

This document was prepared as an account of work sponsored by an agency of the United States Government. Neither the United States Government. nor the University of California nor any of their employees, makes any warranty, express or implied, or assumes any legal liability or responsibility for the accuracy, completeness, or usefuness of any information, apparatus, product, or process disclosed, or represents that its use would not infringe privately own rights. Reference herein to any specific commercial products, process, or service by trade name, trademark, manufacturer, or otherwise, does not necessarily constitute or imply its endorsement, recommendation, or favoring by the United States Government or the University of California. The views and opinions of authors expressed herein do not necessarily state or reflect those of the United States Government or the University of California, and shall not be used for advertising or product endorsement purposes.

This report has been reproduced directly from the best available copy.

Available to DOE and DOE contractors from the Office of Scientific and Technical Information

P.O. Box 62, Oak Ridge, TN 37831

Prices available from (615) 576-8401, FTS 626-8401

Available to the public from the

National Technical Information Service

U.S. Department of Commerce

5285 Port Royal Road

Springfield, VA 22161 


\title{
LASNEX Modeling of Target Expansion in the ETA-II Experiment
}

\author{
by
}

\author{
Darwin D.-M. Ho
}

\begin{abstract}
Summary
We have used the hydrodynamics code LASNEX to model the hydro-expansion of the tantalum target for the ETA-II experiment. The electron beam has kinetic energy of $6 \mathrm{MeV}$ and has a total energy ranges from 720 to $1440 \mathrm{~J}$. The electron beam profile resembles that of a Bennett pinch. The radius for the full-width-at-half-maximum ranges from 1 to $3 \mathrm{~mm}$. For all these parameters, simulations show that the electron beam is able to ablate the central portion of the target. The expansion velocity of the target ranges from about $10^{4}$ to $5 \times 10^{5} \mathrm{~cm} / \mathrm{s}$. The target is hot enough so that the surrounding low-density air is ionized and is expanding at a considerably higher velocity than the target itself. Therefore, care must be taken during the experiment to ensure that the measurement is for the tantalum and not for the ionized air front.
\end{abstract}

\section{Description of the LASNEX Simulation and Discussion of the Results}

The typical target in the ETA-II experiment is made of tantalum with a density of 16.6 $\mathrm{g} / \mathrm{cm}^{3}$ and a thickness of $1 \mathrm{~mm}$. The target is surrounded by low-density air with a density about $1.5 \times 10^{-6}$ torr. The electron beam has kinetic energy of $6 \mathrm{MeV}$ and a current of $2 \mathrm{kA}$. The pulse has a duration of $60 \mathrm{~ns}$ and the total beam energy is about $720 \mathrm{~J}$. In this memo, we simulate the target expansion using the radiation hydrodynamics code LASNEX.

The initial configuration of the mesh is shown in Fig. 1a and the enlarged plot of the mesh near the target is shown in Fig. 1b. In order to speed up the simulation, we only simulate the left-hand-side of the problem. The electron beam is assumed to be coming in from the left and therefore the hydro-expansion is more rapid on the left-hand side. This is because the rate of electron energy deposition decreases with penetration depth. Note that the stopping distance for electrons at $6 \mathrm{MeV}$ in normal density tantalum is a little greater than $2 \mathrm{~mm}$. In Fig. 1, no left and right motion is allowed at the right-hand boundary but the material is allowed to slide up and down along this boundary.

The energy deposition into the target by the electrons is simulated by putting on energy source in the target. The intensity of the source has a radial profile that resembles a Bennett pinch with full-width-at-half-maximum ranges from 1 to $3 \mathrm{~mm}$. The energy source has an intensity that decreases with the depth of the penetration. Since we only model the lefthand-side of the problem, we assume the energy deposited on the left-hand-side is half of the tutal energy, i.e., $360 \mathrm{~J}$ (case I). We then doubled this to $720 \mathrm{~J}$ (case II) to investigate the hydro-motion when the electron beam intensity is increased. For both cases I and II, the radius of full-width-at-half-maximum of the Bennett profile is $3 \mathrm{~mm}$. For case I, the spatial energy dependence of the energy source results in radial and axial temperature profiles as shown in Figs. $2 a$ and $2 b$, respectively, for the time corresponding to the end of the pulse at $60 \mathrm{~ns}$. Using the energy source in the target to model the electron-target interaction is valid 
here since for all the cases simulated here the target does not expand much during the pulse (see Fig. 3).

We ran the problem to $5 \mu \mathrm{s}$. Figures $4 \mathrm{a}, 4 \mathrm{~b}$, and $4 \mathrm{c}$, show the target configuration, temperature profile along the axis, and average ionization contours, respectively, for case I at $5 \mu \mathrm{s}$. The corresponding plots for case II are shown in Figures 5a, 5b, and 5c. From these plots, we notice that the electron beam is able to ablate the central part of the target since the temperature for vaporization of tantalum is about $5700 \mathrm{~K}$. The average expansion velocity for the target along the axis to the left is about $10^{4}$ and $2 \times 10^{4} \mathrm{~cm} / \mathrm{s}$ for cases I and II, respectively. The corresponding distance moved in $5 \mu \mathrm{s}$ is therefore about 0.5 and 1 $\mathrm{mm}$ as shown in Figs. $4 \mathrm{a}$ and $5 \mathrm{a}$. Figures $4 \mathrm{c}$ and $5 \mathrm{c}$ show that the target temperature is sufficiently high so that the surrounding air is ionized. The expansion velocity of the ionized air is considerably higher than that of the tantalum. Figures $4 \mathrm{c}$ and $5 \mathrm{c}$ show that in $5 \mu \mathrm{s}$ the ionization front of the air has moved 2 and $3 \mathrm{~mm}$ for case I and case II, respectively.

The last simulation (case III) that we have performed is identical to case I except that the Bennett profile of the energy deposition is more peaked at the center (radius at fullwidth-at-half-maximum is about $1 \mathrm{~mm}$ vs $3 \mathrm{~mm}$ for case 1 ). The resultant radial temperature profile near the target surface at the end of the pulse is therefore also more peaked at the center as shown in Fig. 6. The higher temperature along the axis results in a higher expansion velocity of the air and the target. As a consequence, the expansion of the air and the target shown in Fig. $7 \mathrm{a}$ at $0.3 \mu \mathrm{s}$ is already greater than that for case I at $50 \mu \mathrm{s}$ shown in Fig. 4c. The temperature along the axis, the average ionization, and the density along the axis for case III at $0.3 \mu \mathrm{s}$ are shown in Figs. $7 \mathrm{~b}, 7 \mathrm{c}$, and $7 \mathrm{~d}$, respectively. The average expansion velocity of the target along the axis is about $5 \times 10^{5} \mathrm{~cm} / \mathrm{s}$ and the distance moved travelled by the target at $5 \mu \mathrm{s}$ is about $2 \mathrm{~mm}$. Comparing Figs. 7a and 7c, we note that because of the high temperature, the ionization front of the air moves faster than the front for the hydro-expansion of the air.

Note that the peak temperatures shown in Fig. 6 for case III is more than five times higher than that for case I. The average expansion velocities for these two cases are, however, not proportional to the square root of the temperature (or, proportional to the sonic velocity -- i.e., the sonic velocity measured at the end of the pulse on the surface of the target along the axis). This is becasue in case I, although the maximum temperature at the end of the pulse on the surface is slightly above the temperature for vaporization, the temperature drops below the temperature for vaporization just slightly below the surface. In addition, the temperature drops somewhat during the expansion. Therefore, the average expansion velocity for this case is below the sonic velocity. On the other hand, in case III, the temperature along the axis is considerably above the tempcrature for vaporization and the average expansion velocity is close to the sonic velocity. 

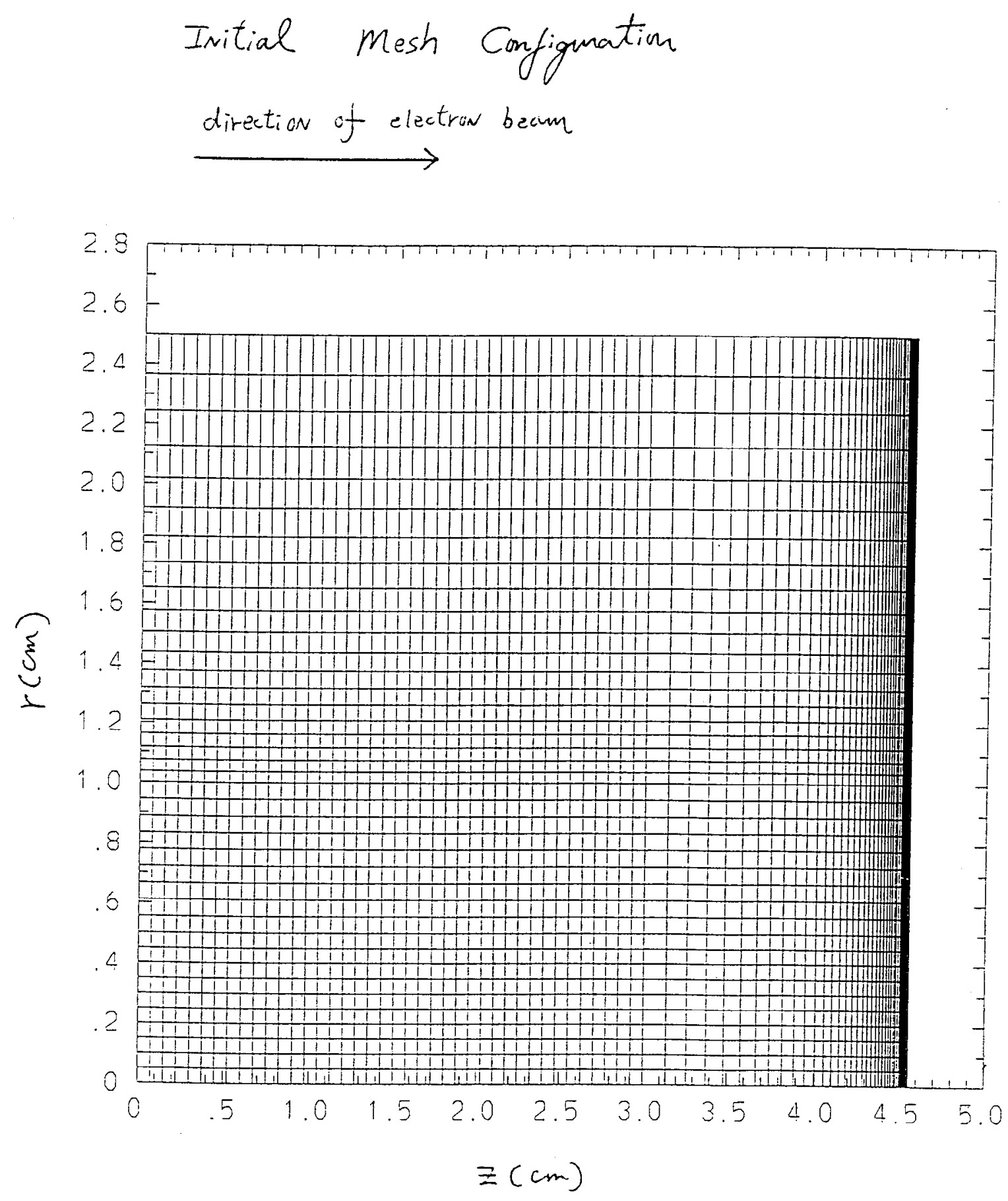

Fig. Ia 
Initial Mesh Configunatum neon the Target

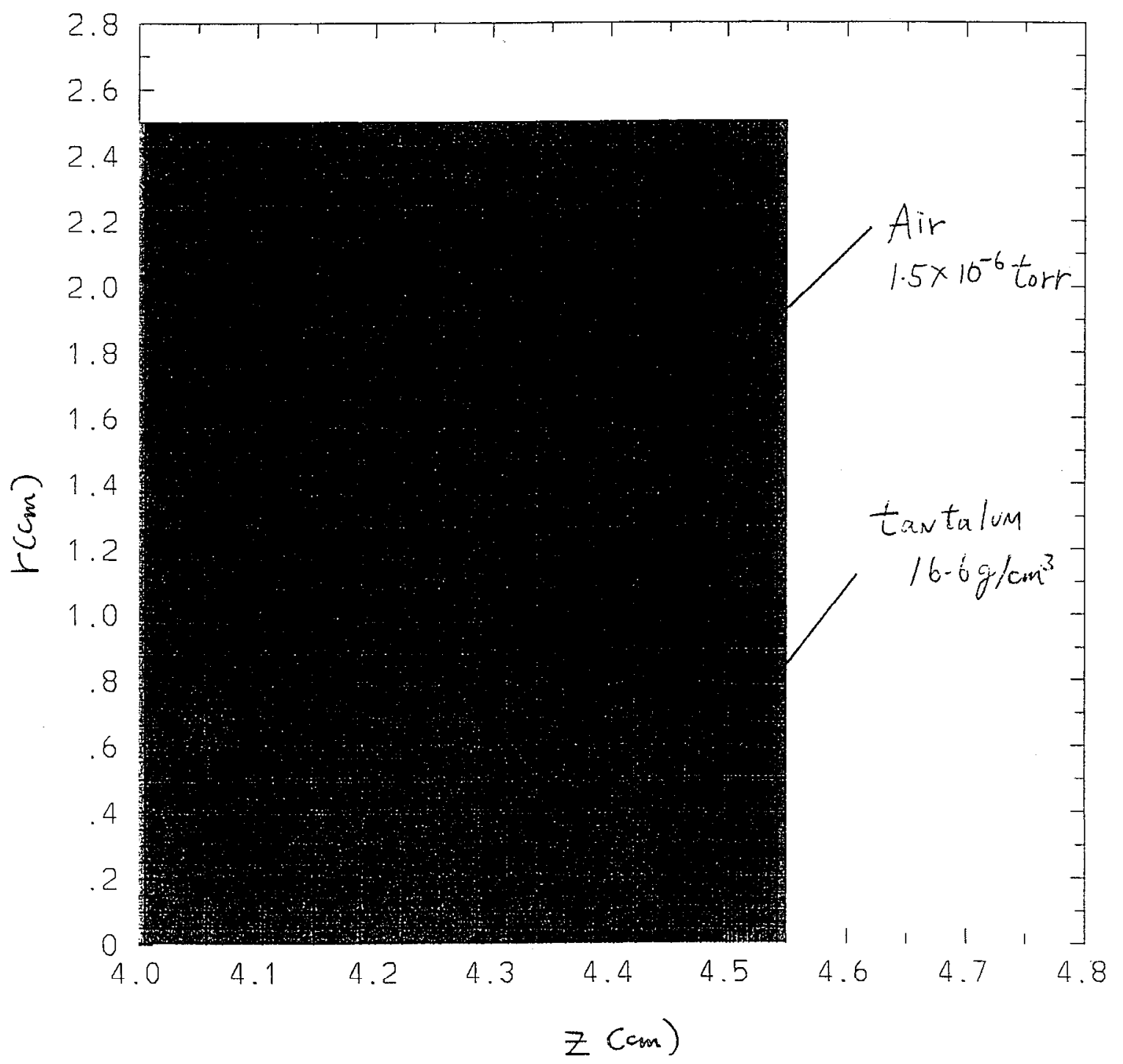

Fig. Ib 
Mesh \& Tanach Comfigmantion at the end of the Pulse at $60 \mathrm{~ns}$

Case I: total hear n energy $=720 \mathrm{~J}$, radius of the Bewuetf profile at $=3 \mathrm{~mm}$

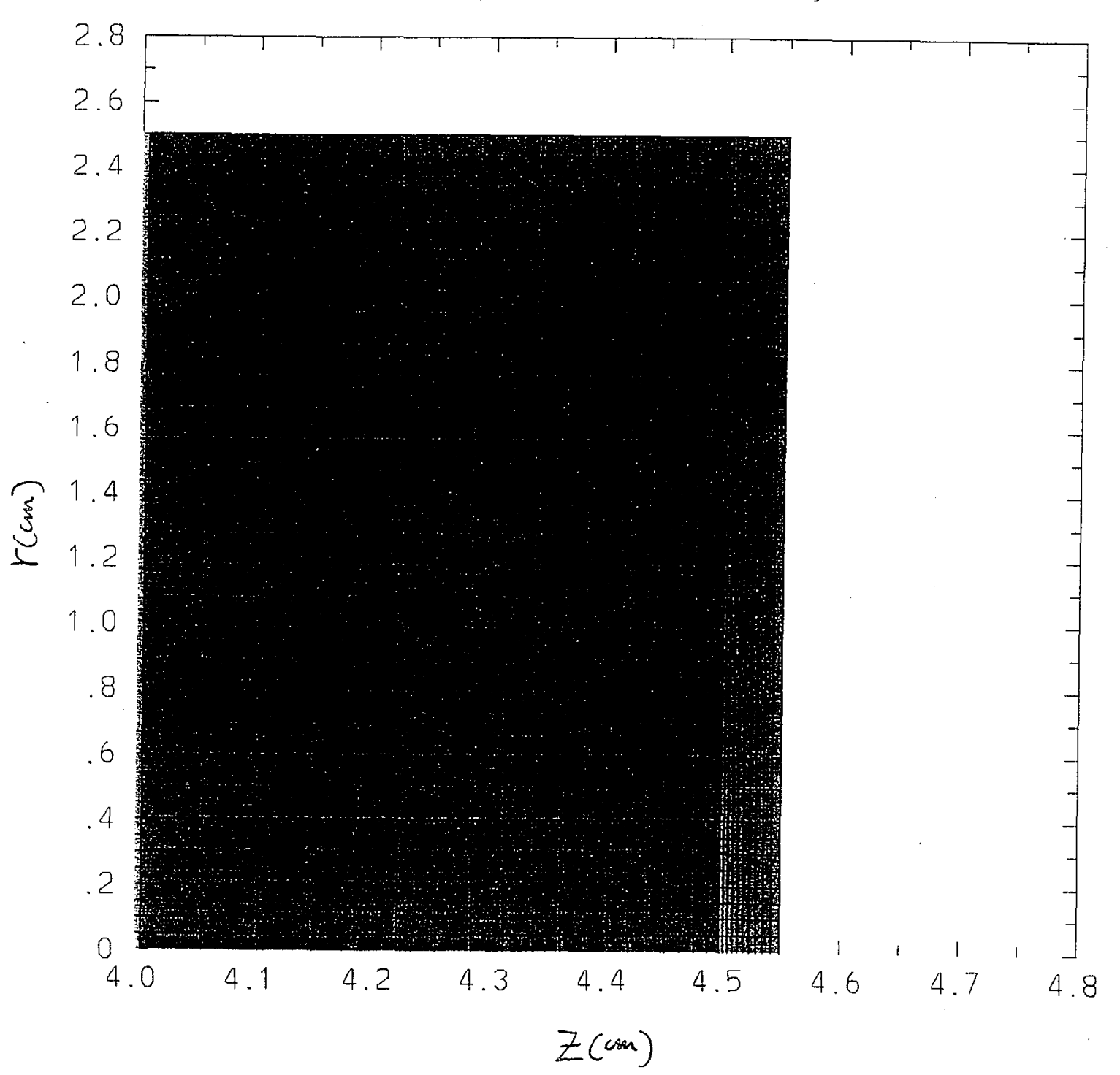

Fig. 3 
Taragt Corfigunation at $5 \mathrm{MS}$

case I:

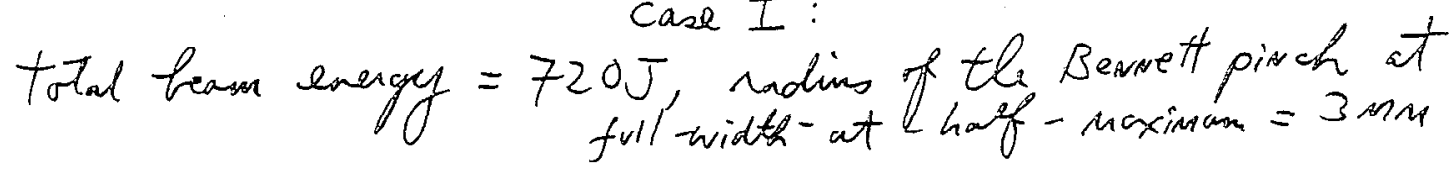

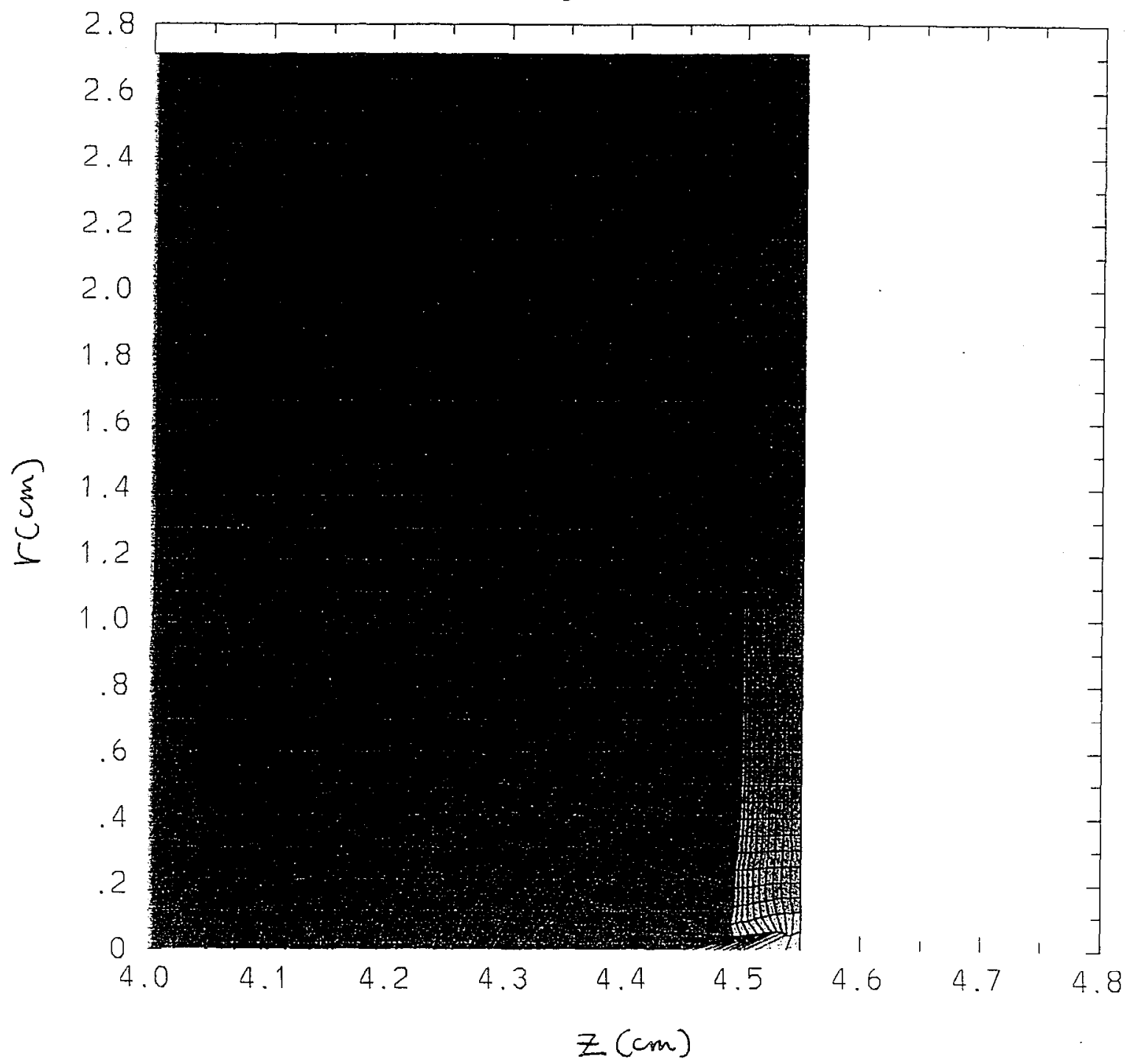

Fig. 4 a 
Temperature along the axis

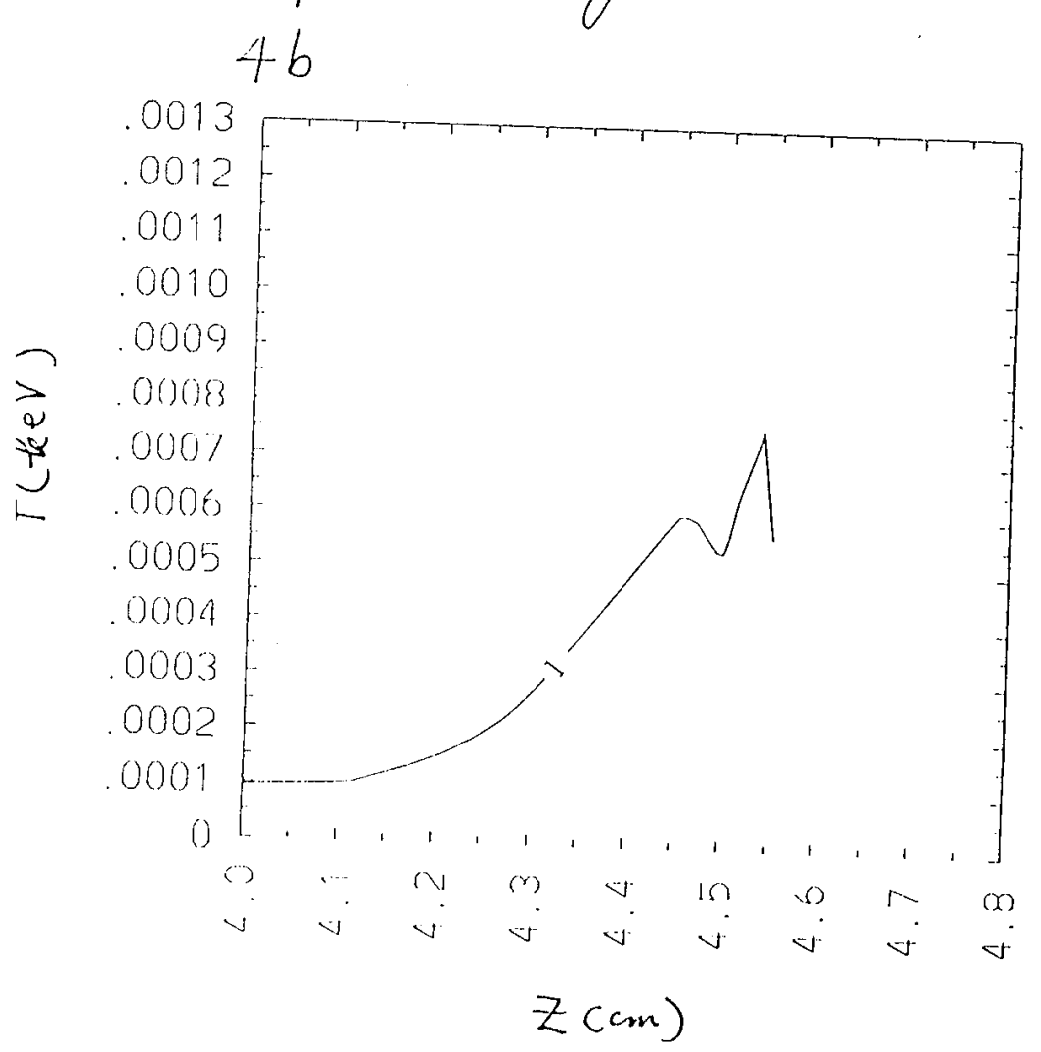

Average ionization $\bar{z}$

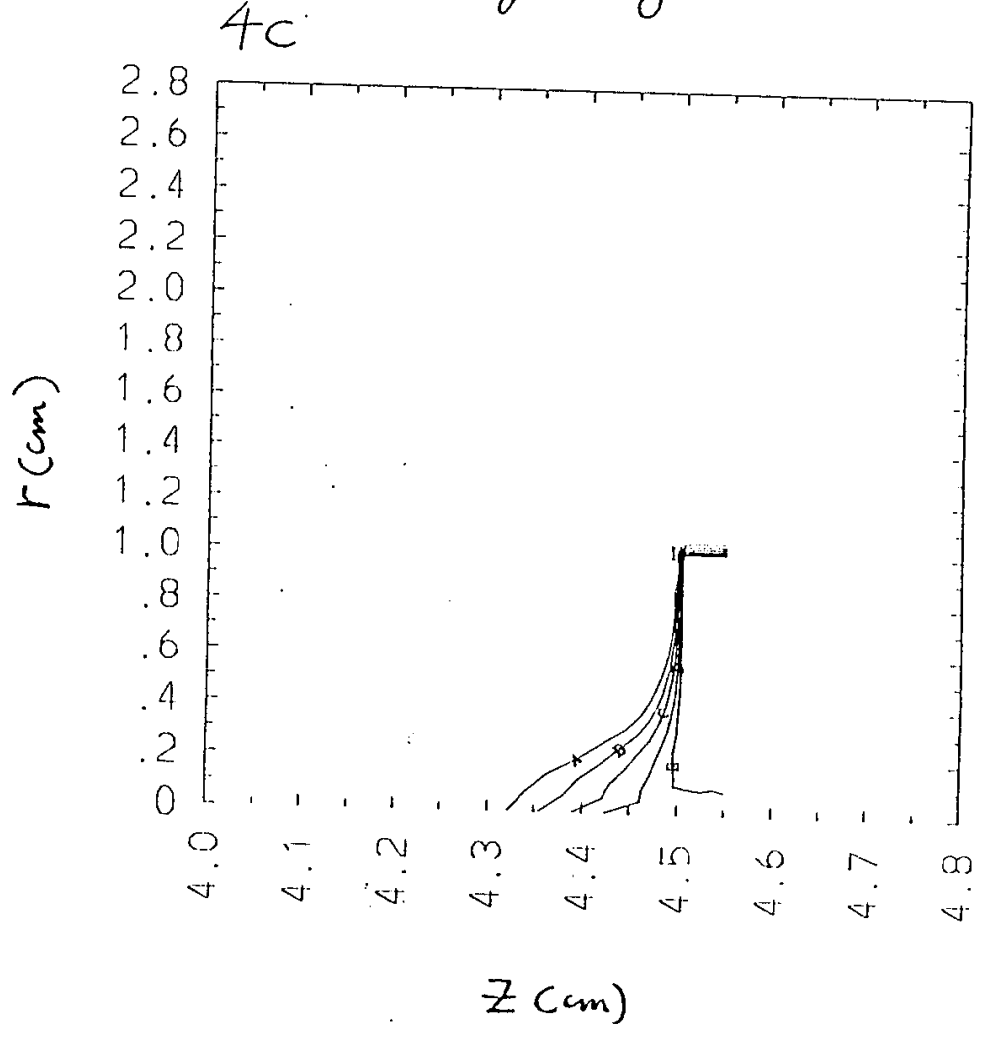

A $1.000 E+00$

$2.000 E+00$

C $\quad 3.000 E \cdot 00$

Fig. 46

Fig. $4 \mathrm{C}$ 
Tanagt Configmantion at $5 \mathrm{~ms}$

case II
total beam energy $=1440 \mathrm{~J}$, radius ofe the Berwett pivch at full-width-at-half-maximum $=3 \mathrm{~mm}$

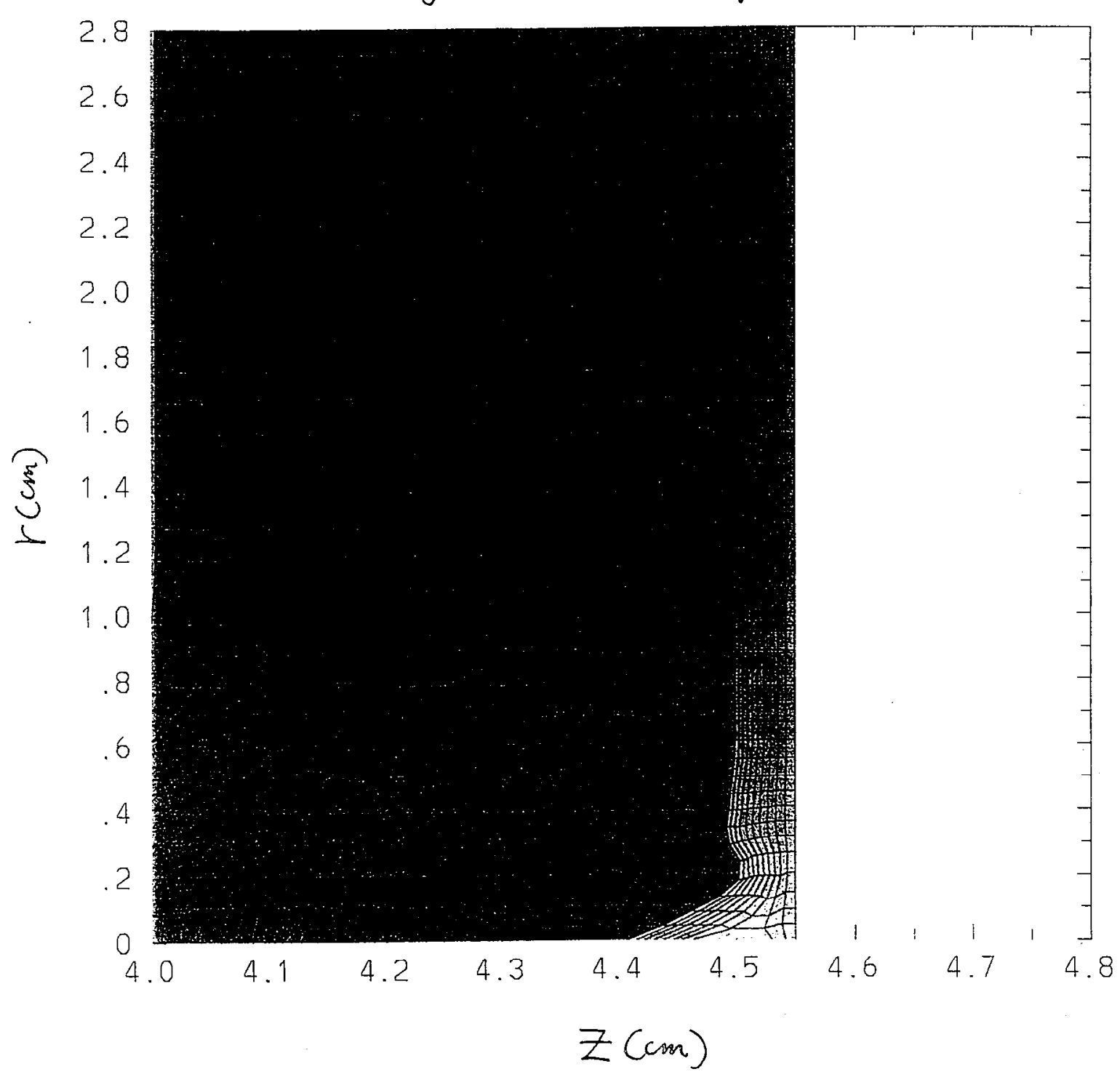

dewsity g/ $\mathrm{cm}^{3}$

1

Fig. 5 a 
Case II

Temperate Along the Axis

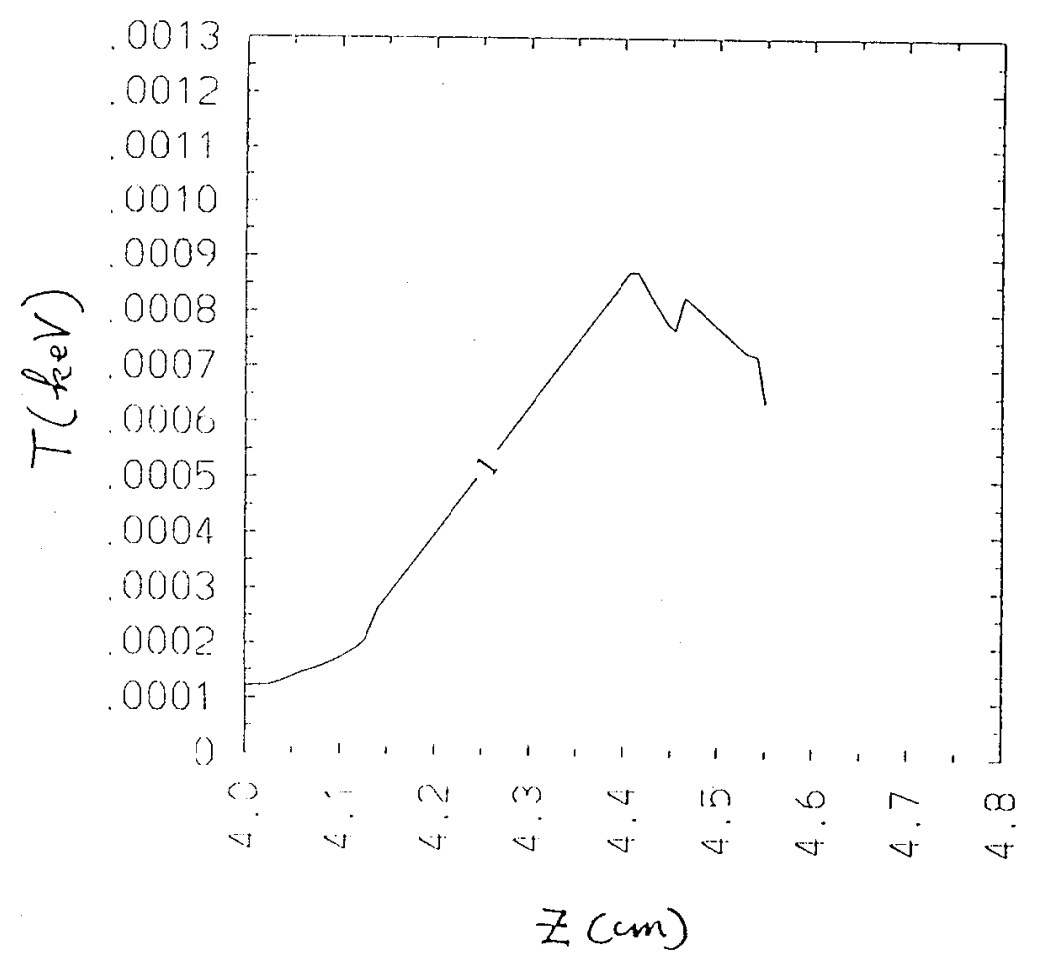

Average Ionization

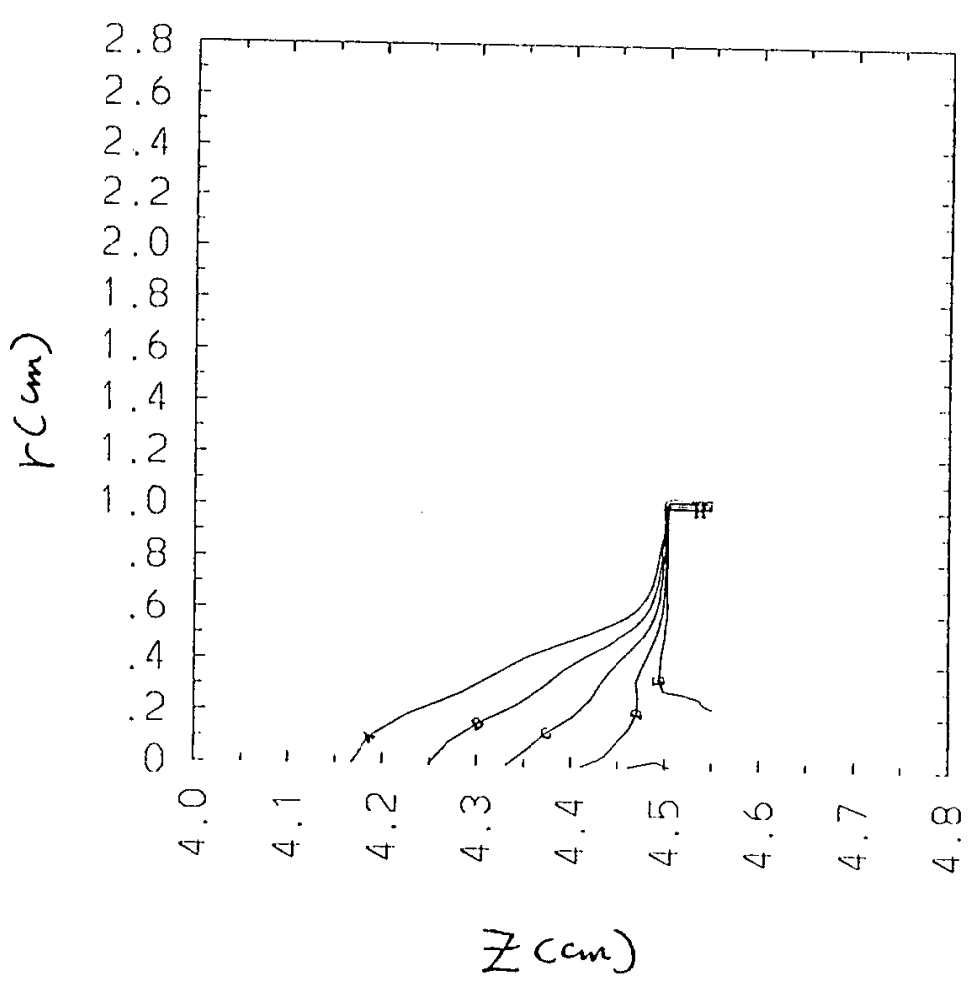

A $\quad 1.000 E \cdot 00$

B $2.000 E \cdot 00$

C $3.000 E+00$

$\begin{array}{ll}\text { D } & 4.000 E+00 \\ \text { E } \quad 5.000 E+00\end{array}$

$i$

Fig. $5 b$

Fig. $5 \mathrm{C}$ 
Radial Temperature at the End of the Pulse

Case III vs Care I

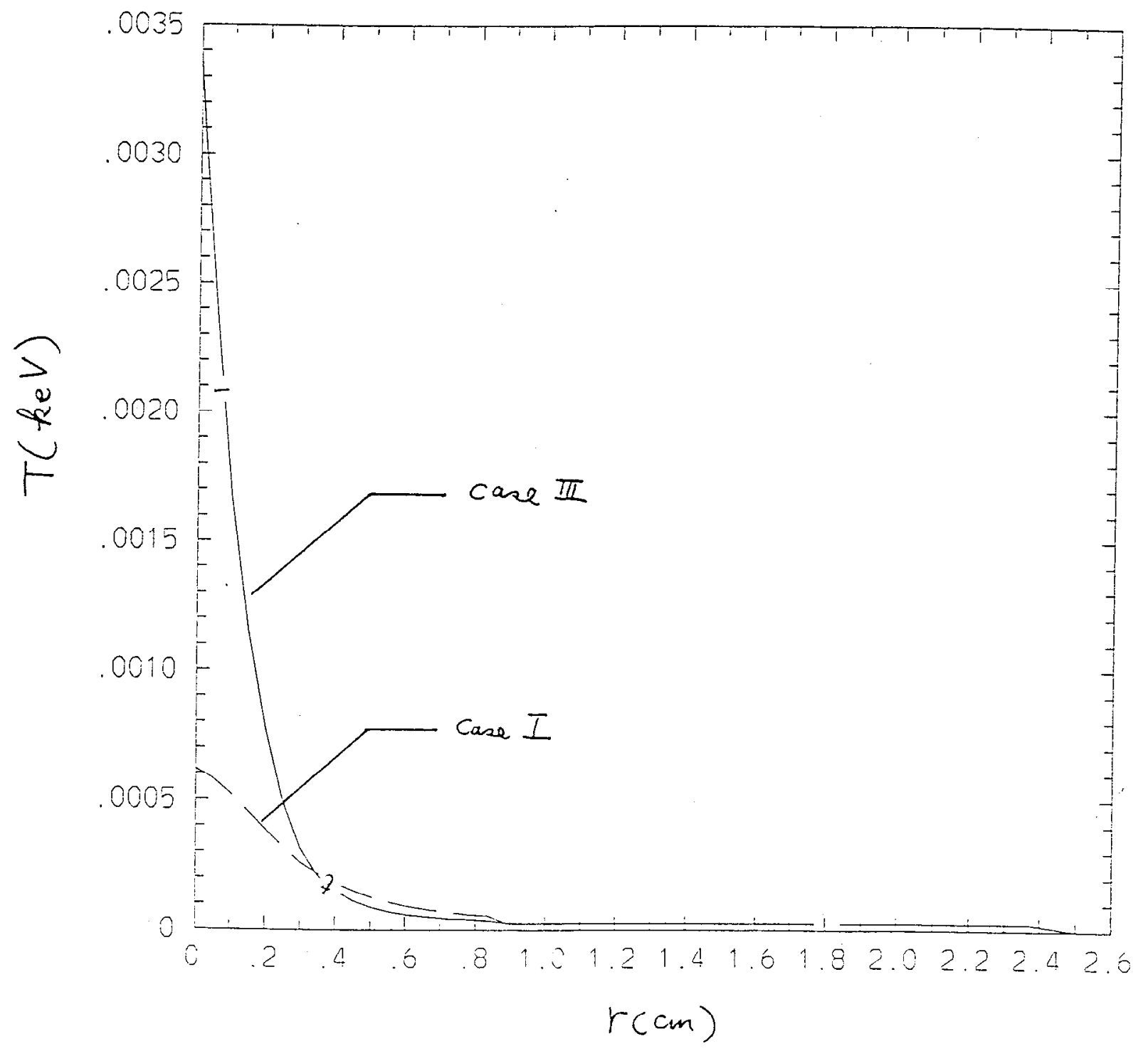

Fig. 6 
Target Compigmation at $0.3 \mu \mathrm{s}$ density $\mathrm{g} / \mathrm{c}$ Case III

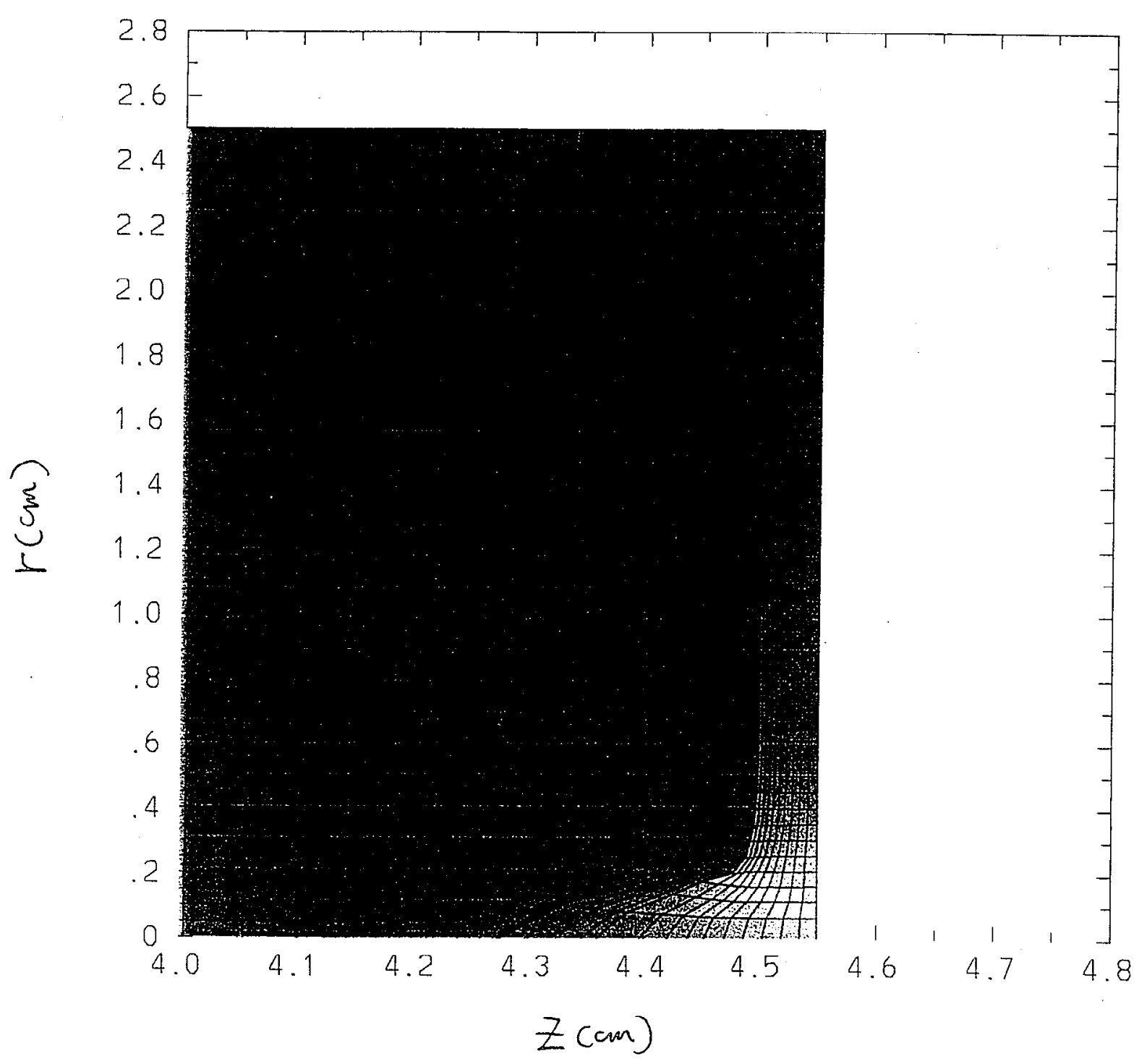

Fig. $7 a$ 


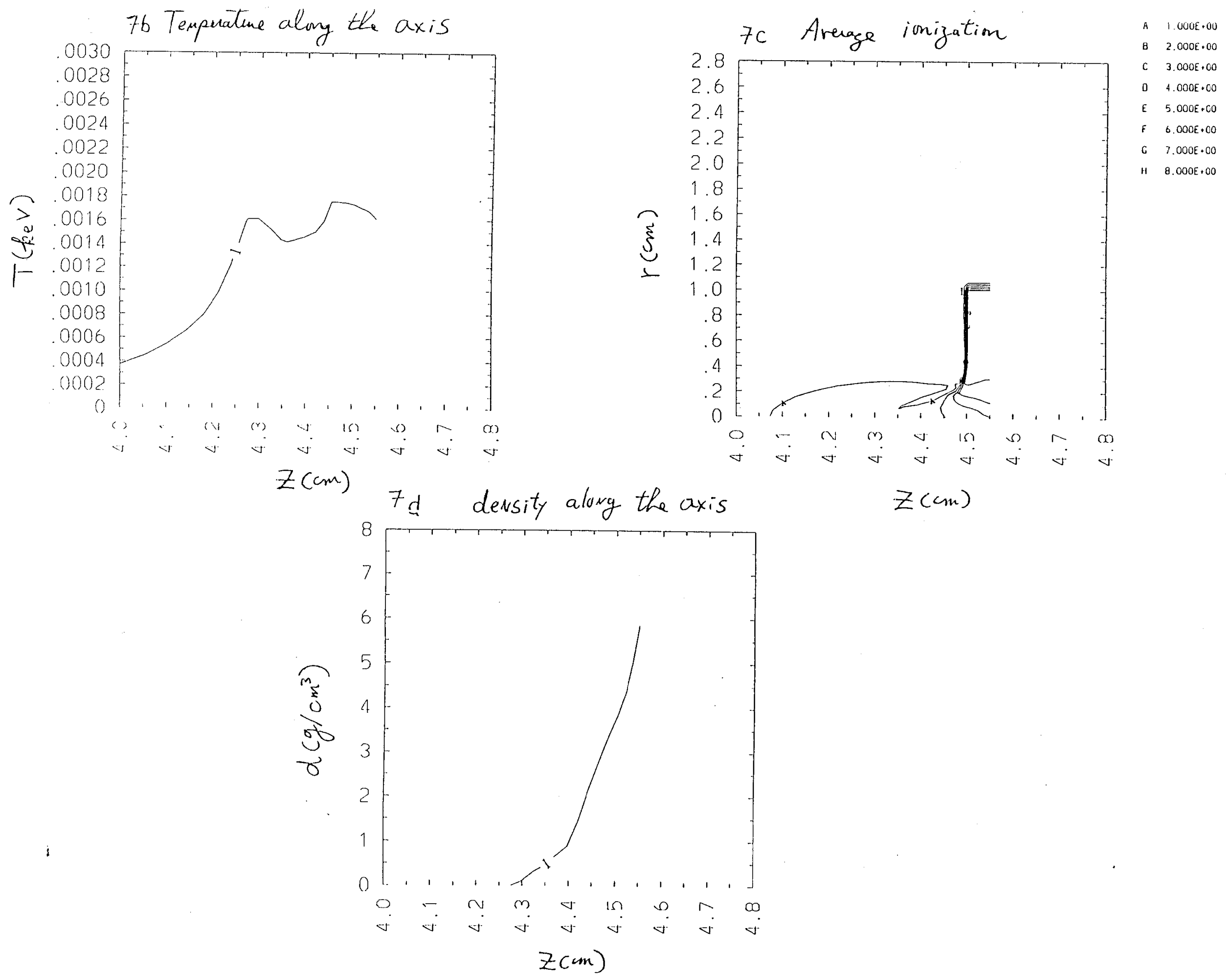

